\title{
Algunas reflexiones sobre el envejecimiento
}

\author{
Some reflections about aging
}

En agosto de 2016 la Academia Chilena de Medicina dedicó su VI Seminario de Bioética al tema del envejecimiento. Con el aporte del Profesor Marc Antoni Broggi de la Academia de Medicina de Cataluña y de un selecto grupo de expositores nacionales se abordaron los desafios que enfrenta la sociedad contemporánea ante el creciente envejecimiento poblacional. Se trata de un fenómeno global, atribuible a múltiples factores que incluyen los avances cientificos, médicos, de saneamiento ambiental, estilos de vida, educación y otros. El resultado es el gran aumento de la expectativa de vida alcanzado, el que en los últimos 100 años es mayor al ocurrido en los 50 siglos anteriores. En cifras la expectativa de vida al nacer ha aumentado desde 47 años en el quinquenio 1950-55 como promedio mundial, a 71,5 años calculados para el quinquenio 2020-25. En Chile, para esos mismos quinquenios, el aumento es de 54,8 a 82,2 años. Otra perspectiva es la proporción de adultos mayores en la población, lo cual en nuestro país significa que el porcentaje de mayores de 60 años ha aumentado de 9,5\% en 1990 a $14,75 \%$, en 2015, lo que significa un aumento de 55\% en 25 años.

Los cambios señalados continúan y generan graves problemas a niveles personales, familiares, poblacionales, previsionales, económicos y en el aumento de enfermedades crónicas y discapacitantes. Por eso se habla hoy de una "revolución del envejecimiento" que plantea dificiles interrogantes, muchas de ellas sin respuestas claras. La primera de ellas es la distinción entre expectativa o esperanza de vida al nacer y la duración posible de la vida (life span). La expectativa de vida varía según las causas y tasas de mortalidad general, mientras la duración posible de la vida es la propia de cada especie de seres vivos, lo que depende de su capacidad biológica, de acuerdo a su genética y a los cambios adaptativos que ocurren a través de la evolución. El gran aumento de la expectativa de vida en las últimas décadas no se explica por un aumento de la duración de la vida de la especie sino por el mayor número de personas que llegan a edades avanzadas.

Se ha logrado prolongar la duración de la vida en algunas especies a través de intervenciones experimentales de prevención o de reversión del envejecimiento aplicando técnicas de medicina regenerativa que intenta reemplazar o reparar el daño celular y molecular acumulado en el tiempo. Sin embargo, se especula si esto es posible y se duda si podría ser deseable para la especie humana. Ante esta hipotética posibilidad muchos piensan en la necesidad de precisar la orientación de la medicina, con sus diversas investigaciones e intervenciones. La propuesta es aumentar los esfuerzos para lograr un envejecimiento más lento, la prevención y la postergación de las enfermedades asociadas a esta etapa de la vida, contribuyendo así a mejorar la capacidad funcional y la calidad de vida de las personas de mayor edad. En otras palabras el propósito sería no pretender un aumento de la duración de la vida humana, sino centrar los esfuerzos en lograr un aumento del tiempo saludable en los últimos años de vida de cada persona.

Si se piensa el tema en una dimensión más personal que poblacional o de investigación, el esfuerzo de la medicina debería ser la disminución del sufrimiento debido a enfermedades asociadas a la edad avanzada, junto con la búsqueda de sentido y significado de la experiencia irrenunciable de la finitud de la vida. Este es uno de los fines de la medicina propuestos por Hastings Center, junto a la prevención de la muerte prematura y la ayuda para una muerte en paz. Otra dimensión fundamental es que las personas mayores deben ser los dueños de su vida por el mayor tiempo posible, tomando sus decisiones en salud, cumpliendo sus metas y definiendo sus preferencias y opciones de tratamiento para las etapas en las cuales ya no puedan decidir. Esto se traduce en expresiones claras de su voluntad, tanto en forma verbal con sus familiares y sus médicos tratantes, como por escrito mediante documentos de voluntades anticipadas. De esta manera estarán ejerciendo su autonomía y podrán vivir la vejez de ma- 
nera positiva como una parte importante de su ciclo vital, de acuerdo a su cultura, valores, creencias, esperanzas y temores. En último término podrán también "apropiarse" de su muerte, como lo expresa Broggi, lo cual significa que el final de su vida ocurra respetando sus voluntades.

Si se piensa el tema del envejecimiento desde una perspectiva ética y social, la prolongación de la vida tiene consecuencias demográficas, laborales y económicas muy complejas. Se llega así a lo que estamos viviendo con un aumento progresivo del número de personas no productivas que necesitan ser mantenidas y atendidas en sus patologías crónicas por largo tiempo. Las intervenciones médicas han llevado a una progresiva bio-medicalización que, además de prolongar los últimos años de vida en condiciones frecuentemente no saludables y de sufrimiento, dificulta la integración de la vejez y también de la muerte, entendidas como parte de la vida con su sentido y significados. Por otra parte, la desvalorización de la vejez, tan frecuente en nuestra pragmática cultura contemporánea, favorece la discriminación y la postergación de las personas mayores, particularmente de las que viven en situación de pobreza.

Los temas planteados han generado preguntas abiertas con variadas respuestas posibles. Desde ya Daniel Callahan propuso hace 25 años la necesidad de poner límites a las prestaciones médicas en personas mayores, lo cual ha sido fuertemente criticado, pero el tema continúa vigente. La pregunta es si los fines de la medicina, individual y socialmente, deben o pueden ser los mismos para la atención médica de personas jóvenes o de adultos en edad media, que para la atención de adultos mayores. Su propuesta fue que quienes ya han cumplido sus proyectos vitales, o quienes son portadores de patologias y condiciones severamente limitantes, deben recibir el mejor cuidado y apoyo en las prestaciones de salud, pero que no deberían recibir los máximos esfuerzos curativos ni generar máximos gastos en salud. Poner estos límites como políticas de salud tendrá inevitablemente el riesgo de ser interpretado como un forma de discriminación o como una menor valoración de los mayores. Aplicar estos límites en casos individuales tiene, como lo vivimos a diario en la práctica clínica, la dificultad que por el frecuente rechazo o temor a la muerte se realizan tratamientos e intervenciones desproporcionadas y fútiles, aumentando asi el sufrimiento y los costos. El problema se ha hecho aún más dificil porque, desde la publicación del libro de Callahan "Setting limits", se ha incrementado progresivamente el número de adultos mayores. Una proporción creciente de ellos está en estado saludable, tiene actividad y sus propios proyectos de vida y, por lo tanto, el criterio general propuesto no resulta aplicable. Parece razonable entonces emplear un criterio prudente que, ante decisiones clínicas complejas, se considere caso a caso el pronóstico de sobrevida, la funcionalidad y calidad de vida, la voluntad y los valores del paciente, y la proporcionalidad entre el esfuerzo, los riesgos, los costos y la efectividad debidamente demostrada de cada tratamiento. En otras palabras las decisiones necesitan estar centradas siempre en la persona y esto es evidentemente diferente si se trata de personas saludables o de personas mayores con discapacidades funcionales y enfermedades crónicas. La edad cronológica es un dato importante, pero no es por sí mismo un criterio que pueda definir tratamientos o políticas de salud.

Dr. Juan Pablo Beca I.

Profesor titular de Medicina,

Director del Magíster Interuniversitario de Bioética, Facultad de Medicina Clínica Alemana - Universidad del Desarrollo, Miembro Honorario de la Academia Chilena de Medicina

Email:jpbeca@udd.cl 